\title{
OPEN Survival is reduced
}

\section{when endogenous period deviates from $24 \mathrm{~h}$ in a non-human primate, supporting the circadian resonance theory}

\author{
Clara Hozer ${ }^{1}$, Martine Perret ${ }^{1}$, Samuel Pavard ${ }^{2}$ \& Fabien Pifferi ${ }^{1 凶}$
}

Circadian rhythms are ubiquitous attributes across living organisms and allow the coordination of internal biological functions with optimal phases of the environment, suggesting a significant adaptive advantage. The endogenous period called tau lies close to $24 \mathrm{~h}$ and is thought to be implicated in individuals' fitness: according to the circadian resonance theory, fitness is reduced when tau gets far from $24 \mathrm{~h}$. In this study, we measured the endogenous period of 142 mouse lemurs (Microcebus murinus), and analyzed how it is related to their survival. We found different effects according to sex and season. No impact of tau on mortality was found in females. However, in males, the deviation of tau from $24 \mathrm{~h}$ substantially correlates with an increase in mortality, particularly during the inactive season (winter). These results, comparable to other observations in mice or drosophila, show that captive gray mouse lemurs enjoy better fitness when their circadian period closely matches the environmental periodicity. In addition to their deep implications in health and aging research, these results raise further ecological and evolutionary issues regarding the relationships between fitness and circadian clock.

The circadian clock is a pervasive feature, expressing biological rhythms that control a wide range of physiological, metabolic and behavioral traits ${ }^{1-6}$. It helps coordinating intrinsic biological processes with optimal phases of the daily fluctuating environment. The endogenous period, also called the free-running period or tau, represents the duration of a complete circadian cycle ${ }^{7}$. It lies around $24 \mathrm{~h}$ in most organisms but expresses variance among individuals ${ }^{8}$. It is intrinsically maintained by indirect feedback loops controlling a set of clock genes within the suprachiasmatic nuclei $(\mathrm{SCN})^{9,10}$. Every day, the Earth rotation imposes the entrainment of the circadian clock to the $24 \mathrm{~h}$ light-dark cycles of the environment. Consequently, this daily synchronization between environment and circadian clock is greater in organisms whose endogenous period goes far from $24 \mathrm{~h}$ and may generate some marginal metabolic or physiological costs that could accelerate aging process and affect survival in the long term.

In that regard, the circadian resonance theory assumes a relationship between tau and fitness, via the potential above-mentioned daily metabolic costs: the greater the deviation of tau from $24 \mathrm{~h}$, the lower survival ${ }^{11}$. Indeed, drosophila reared under photoperiodic regimens far from $24 \mathrm{~h}$ displayed reduced survival ${ }^{11,12}$. Wyse et al ${ }^{13}$ found negative correlations between maximum lifespans and tau in several species of rodents and primates ${ }^{13}$; in a study by Libert et al. ${ }^{14}$, mice with endogenous period close to $24 \mathrm{~h}$ lived about $20 \%$ longer than those with shorter or longer $\operatorname{tau}^{14}$. These studies provide evidence that keeping an endogenous period far from $24 \mathrm{~h}$ increases mortality. We thus wondered if a correlation between tau and mortality could be verified in one single primate species.

To address this issue, we focused on an emerging model in neurosciences, the gray mouse lemur (Microcebus murinus). This small nocturnal primate originates from Madagascar and displays aged-related impairments similar to those found in humans ${ }^{15-17}$, including circadian rhythms alterations, such as locomotor activity fragmentation or sleep deterioration ${ }^{18-20}$. In captivity, the gray mouse lemur can live to age $12^{17}$ and its half-life is approximately 5-6 years ${ }^{21,22}$, whereas the lifespan is significantly lower in the wild ${ }^{23}$. In natural habitat, substantial seasonal variations compel drastic changes in mouse lemur's metabolism and behavior. The hot rainy

${ }^{1}$ Unité Mécanismes Adaptatifs et Evolution, Muséum National d'Histoire Naturelle, CNRS, 1 Avenue du Petit Château, 91800 Brunoy, France. 'Unité Eco-Anthropologie (EA), Muséum National d'Histoire Naturelle, CNRS, Université de Paris, 75016 Paris, France. ${ }^{凶}$ email: fabien.pifferi@mnhn.fr 

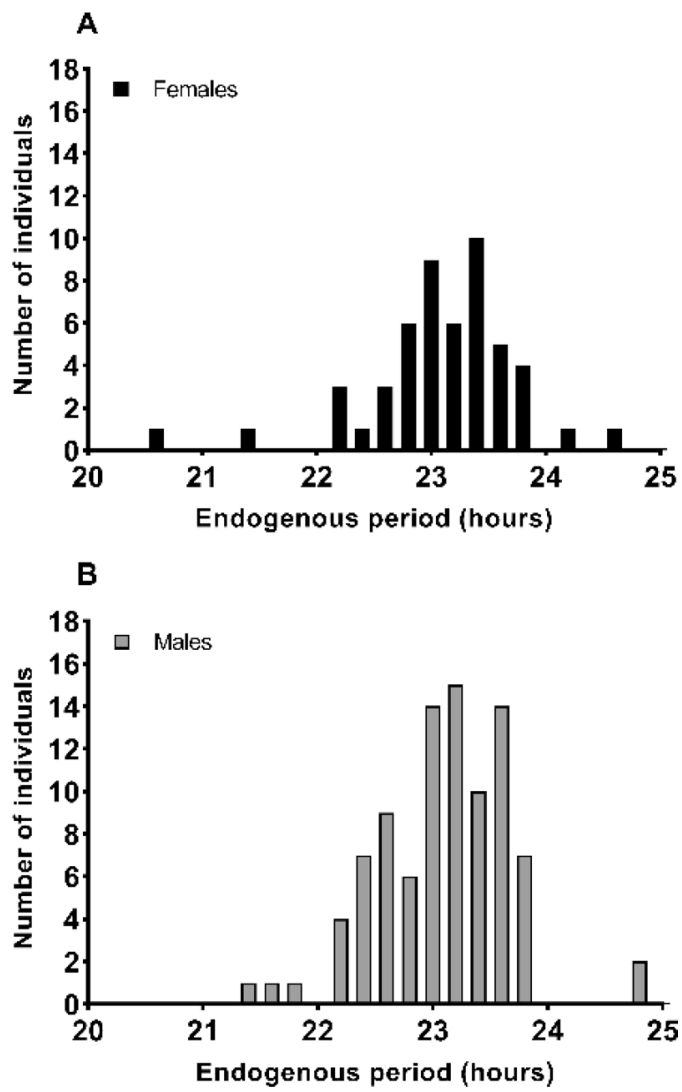

Figure 1. Endogenous period repartition in the 51 female (A) and 91 male (B) mouse lemurs tested. Most of the endogenous periods were less than $24 \mathrm{~h}$, only 4 individuals had a tau higher than $24 \mathrm{~h}$.

season (or summer-like season), characterized by long photoperiod and abundance of resources corresponds to high levels of metabolic activity, as well as reproductive behavior. Rather, during the cooler dry season (or winter-like season), food scarcity and low temperatures force the gray mouse lemur to considerably slow down its metabolism inducing a global fattening and frequent daily phases of hypometabolism ${ }^{24,25}$. These seasonal phenotypic changes are only triggered by the photoperiod: when exposed to photoperiod shorter than $12 \mathrm{~h}$, the gray mouse lemurs exhibits a winter phenotype, whereas it displays a summer phenotype when exposed to a photoperiod greater than $12 \mathrm{~h}^{17,26}$.

Recently, we reported that mouse lemurs raised under light-dark cycles of $26 \mathrm{~h}$ exhibited higher daily body temperature and metabolic rate than animals kept in natural lighting conditions $(24 \mathrm{~h})$, demonstrating the existence of potential metabolic and physiological costs of clock synchronization when endogenous and external rhythms deviate ${ }^{27}$. Do these costs affect the survival of adult individuals? We analyzed how tau affected survival in 142 mouse lemurs. In males, the deviation of tau from $24 \mathrm{~h}$ substantially increased mortality, particularly during the inactive season (winter), whereas it did not affect mortality in females.

\section{Results}

Distribution of tau and correlation with age. As found in many nocturnal species ${ }^{8}$, the gray mouse lemur clock oscillates with a period of less than $24 \mathrm{~h}$ (Fig. 1). Only 2 males and 2 females had an endogenous period greater than $24 \mathrm{~h}$. Mean endogenous periods were $23.09 \pm 0.58 \mathrm{~h}$ and $23.10 \pm 0.64 \mathrm{~h}$ in males and females respectively. There was no significant correlation between tau and age at tau measurement neither in males $(\mathrm{r}=0.13, p=0.20)$, nor in females $(\mathrm{r}=-0.22, p=0.12)$ (Fig. 2). These two results suggest that endogenous period is both specific to individuals and independent of age in this species.

The relationship between tau and survival depends on sex and season. Best selected models for the female and male samples are presented in Table 1. They incorporate only variables Dev.tau, season, the interaction between Dev.tau and season and body mass. All models incorporating the variable lineage had larger AICc such that delta $(\mathrm{AICc})>2$. Individual, maternal and cohort effects did not change the effect sizes of the models. Schoenfeld residuals show that the selected models satisfy the proportionality assumption and martingale residuals did not reveal departure from a linear effect of Dev.tau on mortality. As the effect of Dev.tau remains unchanged among the different selected models and is not modified by other covariates than season, we chose to treat Dev.tau as a categorical variable into a Kaplan-Meier analysis in order to allow graphic representation. We split each sample (males and females) into three categories, corresponding to tertiles of Dev.tau values 


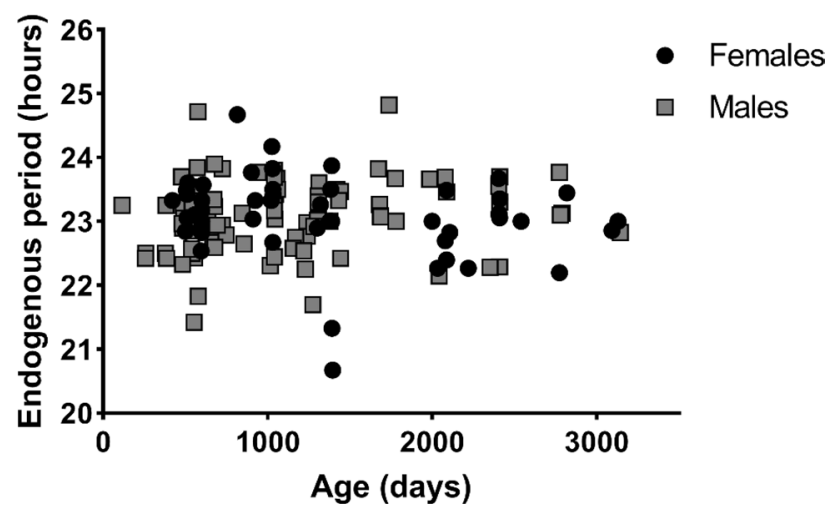

Figure 2. Endogenous periods according to age at measurement in the 142 mouse lemurs tested.

\begin{tabular}{|c|c|c|c|c|c|c|c|c|c|}
\hline \multirow[b]{2}{*}{ Sex } & \multicolumn{2}{|l|}{ Dev.tau } & \multicolumn{2}{|l|}{ Season } & \multicolumn{2}{|c|}{ Dev.tau:Season } & \multicolumn{2}{|l|}{ Body mass } & \multirow[b]{2}{*}{ AICc } \\
\hline & $\beta$ & $p$ & $\beta$ & $P$ & $\beta$ & $P$ & $\beta$ & $p$ & \\
\hline \multirow{6}{*}{ Females } & $-0.17 \pm 0.40$ & 0.67 & - & - & - & - & - & - & 196.7 \\
\hline & $-1.28 \pm 0.95$ & 0.18 & $-0.49 \pm 1.15$ & 0.67 & $1.37 \pm 1.07$ & 0.20 & $0.01 \pm 0.01$ & 0.11 & 196.5 \\
\hline & $-1.12 \pm 0.96$ & 0.24 & $-0.32 \pm 1.15$ & 0.78 & $1.26 \pm 1.08$ & 0.24 & - & - & 196.5 \\
\hline & $-0.27 \pm 0.40$ & 0.49 & - & - & - & - & $0.01 \pm 0.01$ & 0.12 & 196.5 \\
\hline & $-0.21 \pm 0.41$ & 0.60 & $0.88 \pm 0.52$ & 0.09 & - & - & $0.01 \pm 0.01$ & 0.13 & 195.7 \\
\hline & $-0.12 \pm 0.40$ & 0.76 & $0.91 \pm 0.52$ & 0.08 & - & - & - & - & 195.6 \\
\hline \multirow{2}{*}{ Males } & $0.99 \pm 0.39$ & $0.01^{\star}$ & $1.45 \pm 0.59$ & $0.01^{*}$ & $-1.38 \pm 0.53$ & $0.009^{\star *}$ & $0.01 \pm 0.01$ & 0.45 & 427.3 \\
\hline & $1.04 \pm 0.39$ & $0.007^{\star *}$ & $1.46 \pm 0.59$ & $0.01^{*}$ & $-1.39 \pm 0.53$ & $0.008^{\star *}$ & - & - & 425.6 \\
\hline \multirow{2}{*}{ Males in winter-like } & $1.17 \pm 0.42$ & $0.005^{\star *}$ & - & - & - & - & - & - & 144.5 \\
\hline & $1.09 \pm 0.42$ & $0.009^{\star *}$ & - & - & - & - & $0.02 \pm 0.01$ & 0.09 & 144.2 \\
\hline
\end{tabular}

Table 1. Estimated effect sizes $( \pm S D)$ and $p$ values for all variables retained in the selected models in females, males and males in winter-like.

(such as every category included an equal number of individuals greater than 15). For females, the tertiles were $0-40 \mathrm{~min}$ (17 individuals), $40 \mathrm{~min}-1 \mathrm{~h}$ (17 individuals) and $\geq 1 \mathrm{~h}$ (17 individuals). For males, tertiles values were 0-42 min (31 individuals), 42 min-1h04 (30 individuals) and $\geq 1$ h04 (30 individuals) (Fig. 3).

Dev.tau did not influence survival in females (Table 1 and Fig. 3A).

In males, however, Dev.tau affected negatively and significantly the survival. Our best model predicted that every supplementary hour of Dev.tau (i.e. every supplementary hour of tau deviation from $24 \mathrm{~h}$ ) multiplied the risk of death by $2.82\left(=e^{1.04}\right.$, Table 1$)$. Dividing the sample into tertiles of Dev.tau, median survival ages were 2637 days ( 7.22 years), 2170 days (5.94 years) and 1704 days (4.67 years) in the three represented groups respectively, i.e. a reduction of $35 \%$ of median survival between the two extreme curves. Maximum longevities were 3363 days ( 9.21 years), 3772 days (10.33 years), and 3915 days (10.72 years) in the three groups respectively (Fig. 3B).

Besides, the interaction between Dev.tau and season in males was significant as well (Table 1). When only considering the winter-like season, the negative effect of Dev.tau in males on survival was amplified: every supplementary hour of Dev.tau multiplied the risk of death by $3.22\left(=e^{1.17}\right.$, Table 1$)$. Dividing the sample into tertiles of Dev.tau, median survival ages were 3180 days ( 8.71 years), 2844 days ( 7.79 years) and 1413 days ( 3.87 years) in the three represented groups respectively, i.e. a reduction of $56 \%$ of median survival between the two extreme curves. Maximum longevities were 3363 days (9.21 years), 3772 days 10.33 years), and 3871 days (10.60 years) in the three groups respectively (Fig. 3C).

Parametric AFT models were equally but not better supported by the data than proportional hazard model (data not shown).

\section{Discussion}

This study aimed at exploring the relationship between the endogenous period tau and survival in a non-human primate. Our results show no impact of endogenous period on survival in female mouse lemurs. On the other hand, male individuals with endogenous period close to $24 \mathrm{~h}$ were those experiencing a better survival. This effect was particularly significant in winter-like season, corresponding to the non-mating and inactive season. Individuals with tau far from $24 \mathrm{~h}$ had a reduction of median survival up to $56 \%$ compared to individuals with closer tau, suggesting a high adaptive value of maintaining an endogenous period close to $24 \mathrm{~h}$. It is still not clear, however, why tau exhibits such important inter-individual variance but the deviation of tau from $24 \mathrm{~h}$ may bring some advantage in seasonal adaptation by stabilizing the phase angle ${ }^{28}$. So far, the relationship between 


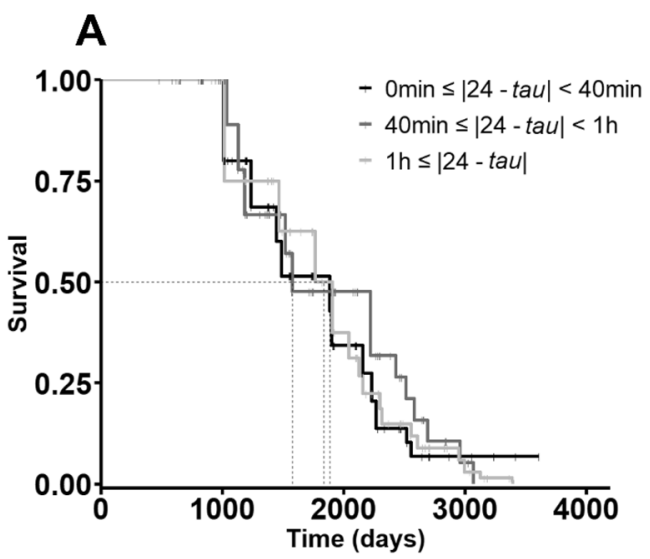

B

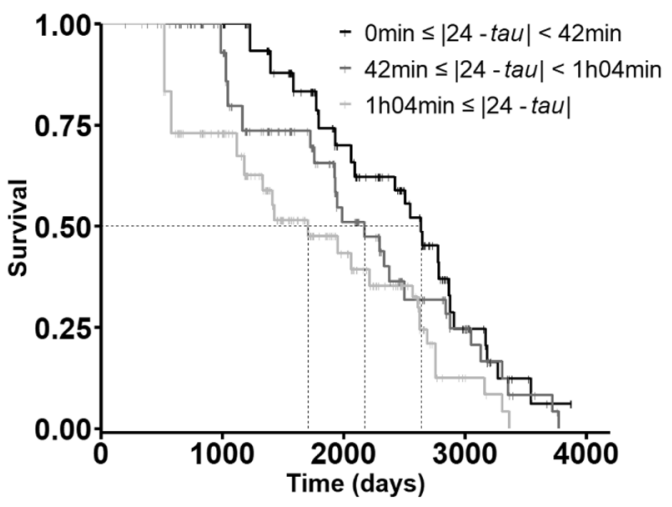

C

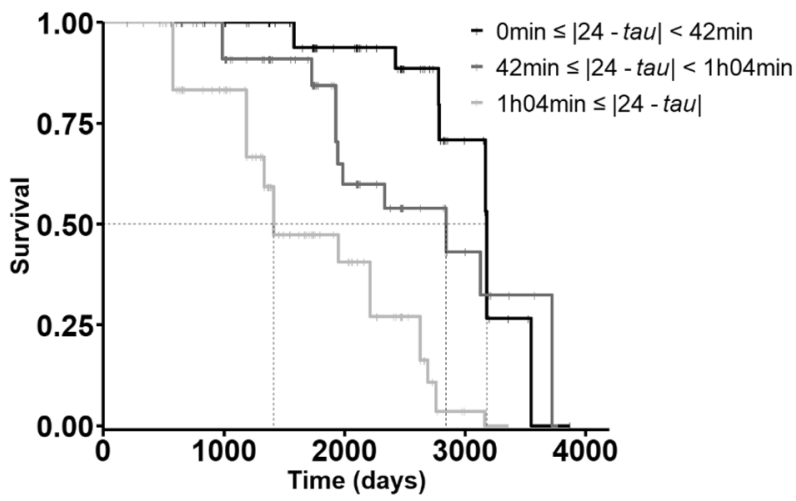

Figure 3. Effect of Dev.tau on the survival of females (A), males (B) and males in winter-like season (C) with increasing age. Individuals were distributed in tertiles to allow graphic representation, corresponding to specific cut-off of absolute deviation of tau from $24 \mathrm{~h}$. Dotted lines correspond to median survivals. Small solid vertical bars correspond to censored data.

endogenous period and survival had been assessed in fruit flies and mice ${ }^{11,14}$. Only one study found a similar relationship in primates, but it applied a totally different experimental protocol, based on interspecific comparisons and maximum lifespans taken from the literature ${ }^{13}$. To our knowledge, our results are the only ones to report a relationship between tau and survival in a single primate species.

Why are the endogenous period and survival related to each other? Pittendrigh and Minis suggested that the daily resetting of the biological clock onto the $24 \mathrm{~h}$ of the environment would engender daily marginal metabolic costs that would accelerate aging and affect survival: the impact of these costs on longevity would be proportional to the deviation of tau from $24 \mathrm{~h}$. In that respect, the median survival ages found in our experiment show clearly that the more tau gets far from $24 \mathrm{~h}$, the more the survival is low. Recently, we observed that mouse lemurs kept in light-dark cycles far from their endogenous period $(26 \mathrm{~h})$ exhibited higher resting body temperature and higher energy expenditure, associated with lower cognitive performances ${ }^{27}$. This study suggests that living under photoperiodic regimen far from endogenous rhythms leads to physiological, metabolic and cognitive costs for 
the organism. It could partially explain the link between tau, longevity and aging. Indeed, biological clock and aging processes are assumed to influence one another. Aging is often associated with rhythm fragmentation, phase advance, sleep disorders, decrease of rhythm amplitude, SCN atrophy ${ }^{29-32}$. Besides, the deterioration of the biological clock is alleged to accelerate and stand at the heart of aging mechanisms ${ }^{33-35}$. In this context, the endogenous period could modulate the rate of aging and indirectly influence organisms' mortality. For example, it was reported that plasma level of interferon- $\gamma$, a well-known biomarker of aging, was negatively correlated to survival in gray mouse lemurs. Interestingly, the plasma level of interferon- $\gamma$ was also negatively correlated with the endogenous period, i.e. the individuals with tau close to $24 \mathrm{~h}$ displayed lower aging biomarkers and greater survival $^{36}$. These observations, along with our results, underline the relevance of an acute and coordinated circadian pacemaker, including endogenous rhythms resonating with the environment cycles, to enhance survival.

Why does the endogenous period correlate with survival in males but not in females? Libert's study focused exclusively on males, but curiously, Pittendrigh and Minis found similar results on males and females. This is intriguing, regarding our results, since insect and mammal clocks are known to display significant similarities ${ }^{37,38}$. We have no clear explanation, but it should not be forgotten that the study included more males than females, increasing the risk of type II statistical error in females. Otherwise, this difference between sexes may be related to mammal sexual circadian specificities, even though a bias towards research on male's circadian clock makes exhaustive comparisons between sexes difficult ${ }^{39}$. Some studies report though that the influence of internal desynchronization on sleep-wake disorders is considerably greater in females than in males, some other mentioned a slower synchronization in females ${ }^{40-43}$. The daily costs of resynchronization due to tau deviation may be negligible in females compared to more important circadian alterations. Unfortunately, sexual comparisons in circadian parameters are little studied in the gray mouse lemur. However it is known that female mouse lemurs deal with seasonal transitions and metabolic costs differently than males, particularly during aging ${ }^{26}$. Facing an environmental metabolic stress, female mouse lemurs seem to better manage their energy expenditure and exhibit more flexible physiological response ${ }^{44-46}$. During aging, males body weight variations collapse whereas females keep displaying clear seasonal mass variations, suggesting a better management of resources ${ }^{21,47}$. Therefore, females may better deal with generated daily metabolic costs due to circadian clock reset and thus would not display survival impairments.

Why does tau correlate with survival in winter-like more than in summer-like? The explanation could lie in the huge physiological and metabolic changes experienced by the gray mouse lemurs between winter-like and summer-like photoperiods. The species has the particularity of being heterothermic, allowing daily phases of hypometabolism (torpor) that occur almost exclusively during the winter-like season, in order to cope with environmental food scarcity and to save substantial amount of energy, even in captive conditions ${ }^{48,49}$. It has been shown that circadian clock and torpor use are closely related ${ }^{50}$. For example, light pollution significantly modifies circadian expressions, with negative repercussions on torpor ${ }^{51}$. If the circadian clock oscillates too far from environmental periodicity, it may imply affectations of torpor efficiency and be deleterious in the long run. Inversely, in summer-like season, during which torpor hardly ever happens, the activation of reproduction investments may require so much energy that reproduction investments in males could overwhelm daily costs engendered by clock synchronization. In addition, IGF-1 (Insulin-like Growth Factor 1) rates exhibit an age-related decrease in male mouse lemurs only during the winter-like season, whereas they remain high and stable during the summer-like season. Interestingly, the winter-like IGF-1 rates are also predictive of survival ${ }^{52}$. It could thus be worthwhile to combine data from tau and IGF-1 in this species, as it is known that circadian rhythms and IGF-1 are closely related ${ }^{53,54}$.

In this study, we showed that Dev.tau was not influenced by age between individuals, but we made the hypothesis that tau was constant over each individual lifetime. It is however not clear if time and more specifically aging do influence the endogenous period or not. In several mammalians, even within the same species, increasing, decreasing or constant endogenous periods with age have been found ${ }^{8,55-58}$. In the gray mouse lemur, the same conflicting observations lead to suggest that tau evolution during aging is due to epigenetic variations between individuals and underline once again that aging is an individual-dependent phenomenon ${ }^{18,59}$. A longitudinal approach is necessary to bring further exhaustive information on the relationship between tau and aging.

These experiments were performed in captive animals, but one may wonder if the endogenous period substantially impacts fitness in nature. Indeed, wild individuals often die before aging ${ }^{23}$ and captive animals are not submitted to predation, food scarcity and less to diseases. Furthermore, the fact that the tested mouse lemurs had such inter-individual variability in tau values might suggest weak selection pressures of tau on survival. Very few studies actually carried out such protocols in natural conditions. It was reported that mice with a mutation in the enzyme casein kinase $1 \varepsilon$ exhibited a short tau $(\sim 22 \mathrm{~h})$ and displayed lower survival and reproduction performances when released in outdoor enclosures ${ }^{60}$. However, the authors could not rule out a potential pleiotropic effect of the mutation, rather than a direct effect of shorter endogenous period to explain reduced lifespans in mutant mice. In natural populations of pitcher-plant mosquitos (Wyeomyia smithii), exposition to light-dark cycles that are integral multiples of the endogenous period maximized fitness by increasing fecundity but surprisingly not by enhancing adult's longevity ${ }^{61}$. In the light of these observations, an interesting study would be to place wild type individuals in semi natural conditions, and to monitor their survival depending on their endogenous period. In captive gray mouse lemurs, an interesting perspective could also be to investigate the relationship between tau and reproduction performances, such as reproductive events or juveniles' recruitment.

To conclude, our results highlighted the negative correlation between great deviation of tau from $24 \mathrm{~h}$ on survival in adult captive male mouse lemurs, even if further investigations are needed to elucidate the ecological implications of sex and season dependence. Our findings show that resonating circadian clocks seem to be highly adaptive features of living organisms and underline the importance of correct clock resetting to enjoy better health. They may have some interesting applications in human societies, where light pollution and drifted ways of life modulate circadian clock adjustments to external world. 


\begin{tabular}{|l|l|l|}
\hline & Males & Females \\
\hline Mean age at death (in years) & $5.98 \pm 2.35$ & $5.69 \pm 2.03$ \\
\hline Mean age at tau measurement (in years) & $3.10 \pm 1.85$ & $3.81 \pm 2.20$ \\
\hline Death from natural causes & 66 & 40 \\
\hline Censored & 25 & 11 \\
\hline
\end{tabular}

Table 2. Mean age at death, age at tau measurement, number of natural deaths and censored individuals in male and female mouse lemurs. Data are presented as mean \pm SD.

\section{Methods}

Animals and ethical statement. All data integrated in the study were taken from the database of the mouse lemur colony of Brunoy (MECADEV, MNHN/CNRS, IBISA Platform, agreement F 91.114.1, DDPP, Essonne, France). These data have been collected between 1996 and 2013. All experiments were performed in accordance with the Principles of Laboratory Animal Care (National Institutes of Health publication 86-23, revised 1985) and the European Communities Council Directive (86/609/EEC). The research was conducted under the approval of the Cuvier Ethical Committee (Committee number 68 of the "Comité National de Réflexion Ethique sur l'Expérimentation Animale”) under authorization number 12992-2018011613568518 v4. Animals were raised in the laboratory under identical nutritional and social conditions. They were all treated using the same experimental methodology, as described below.

Housing conditions. All animals were housed in cages equipped with wood branches for climbing activities as well as wooden sleeping boxes mimicking the natural sleeping sites of mouse lemurs, i.e. tree holes or cavities. The temperature and the humidity of the rooms were maintained at $25-27^{\circ} \mathrm{C}$ and at $55-65 \%$, respectively. In captivity, the artificial daily light-dark cycles within the housing rooms are changed to mimic season alternation, with periods of 6 months of summer-like long days ( $14 \mathrm{~h}$ of light and $10 \mathrm{~h}$ of darkness, denoted 14:10) and 6 months of winter-like short days ( $10 \mathrm{~h}$ of light and $14 \mathrm{~h}$ of darkness, denoted 10:14). Animals were fed ad libitum (with fresh fruits and a homemade mixture, see Dal-pan et al., 2011 ${ }^{62}$ for details).

Telemetry implants. Recording of locomotor activity (LA) was obtained by telemetry at a constant ambient temperature of $25^{\circ} \mathrm{C}$. A small telemetric transmitter weighing $2.5 \mathrm{~g}$ (model TA10TA-F10, DataScience Co. Ltd, Minnesota, USA) was implanted into the visceral cavity under ketamine anesthesia (Imalgene, $100 \mathrm{mg} / \mathrm{kg}$ ip). After surgery, animals returned to their home cage and were allowed to recover for 15 days before start of experiment and continuous recordings of LA. Total recovery was checked by visual inspection of the complete healing of the surgical incision. A receiver was positioned in the cage. Locomotor activity was continuously recorded by the receiver plate, which detected vertical and horizontal movements (coordinate system, DataquestLab Prov.3.0, DataScience Co.Ltd, Minnesota, USA).

Endogenous period measurement. In order to measure the endogenous period tau, individuals included in the survey were isolated and submitted to free-running conditions i.e. total darkness during 7-30 days. Feeding and weighing were planned at random times of the day, so that no bias could be introduced by human activity in the animals' facility. After circadian activity measurements, the light regimen was returned to 10:14 light-dark cycles. Endogenous periods were assessed using Clocklab software (Actimetrics, Evanston, IL, USA).

Mortality data. In total, 142 animals, with 91 males and 51 females were integrated in the study. Thirtysix of them were right-censored (Table 2) because they were alive at the end of the study (i.e. 23 march 2020), had been transferred to another laboratory or had been euthanized during experiments requiring sacrifice. The remaining 106 died natural deaths. Dates of birth and natural death or censoring of each individual as well as the dates of season change were known.

Statistical analyses. Because complex interactions exist between sex, season and mortality ${ }^{17,63}$, we treated males and females separately (for an analysis incorporating males and females together, see supplementary materials Table S1 and Figure S1). We first assessed if there was a relationship between tau and the age at tau measurement, using a Pearson correlation test. For each individual, we then calculated a "Dev.tau" value, which is the absolute deviation of the individual's endogenous period from $24 \mathrm{~h}$ (Dev.tau $=\mid 24-$ tau $\mid)$. The individuals entered the study at tau measurement, and were left truncated at this age. We then investigated the influence of Dev.tau on survival using multi-variate Cox proportional hazard survival analysis ${ }^{64}$. The hazard function (defined as the instantaneous risk that the event of interest, i.e. death, happens) links a baseline hazard function and a vector of covariables via the following function: $h(t \mid y)=h_{0}(t) . e^{\beta y}$, with $h_{0}(t)$ being the baseline hazard function of unspecified distribution, $t$ being the age, and $\beta$ being the parameter quantifying the impact (effect size) of covariate $y$. We first treated Dev.tau as a continuous variable and we included other additional covariates, that are known to affect mortality in this species: season (integrated as a time-varying covariate), and body mass at tau measurement ${ }^{17,22,65}$. We also included the following adjustment variables: lineage entered as fixed effect, as well as birth year, year at tau measurement, identities of individuals and their mothers entered as random variables. We considered all interactions two by two between fixed parameters. We selected the best 
models using a backward procedure by calculating second-order Akaike’s Information Criterion (AICc), conserving only models with delta $($ AICc $)<2$. Since the use of AICc is not appropriate to predict significance of random effects, we compared the effect sizes of models incorporating the random variables $v s$ models that did not, to potentially adjust for interindividual heterogeneity, maternal effects or cohort effects. Verification of the proportionality and the linearity of the models was made using Shoenfeld and martingale residuals. Finally, we constructed parametric Accelerated Failure Time (AFT) models equivalent to the selected Cox models in term of incorporated covariates, to test whether Dev.tau accelerate the speed at which mortality increase with age. We compared them to equivalent parametric Proportional Hazard (PH) models. Both methods assume a Gompertz baseline distribution. This procedure allowed to test whether Dev.tau was related to mortality patterns by changing the rate of aging.

Received: 3 July 2020; Accepted: 8 October 2020

Published online: 22 October 2020

\section{References}

1. Barclay, J. L., Tsang, A. H. \& Oster, H. Interaction of central and peripheral clocks in physiological regulation. In Progress in Brain Research, Vol. 199, 163-181 (Elsevier, 2012).

2. Kyriacou, C. P. \& Hastings, M. H. Circadian clocks: genes, sleep, and cognition. Trends Cogn. Sci. 14, 259-267 (2010).

3. Reinke, H. \& Asher, G. Circadian clock control of liver metabolic functions. Gastroenterology 150, 574-580 (2016).

4. Kalsbeek, A., La Fleur, S. \& Fliers, E. Circadian control of glucose metabolism. Mol. Metab. 3, 372-383 (2014).

5. Richards, J. \& Gumz, M. L. Mechanism of the circadian clock in physiology. Am. J. Physiol. Regul. Integr. Comp. Physiol. 304, (2013).

6. Karatsoreos, I. N., Bhagat, S., Bloss, E. B., Morrison, J. H. \& McEwen, B. S. Disruption of circadian clocks has ramifications for metabolism, brain, and behavior. Proc. Natl. Acad. Sci. USA 108, 1657-1662 (2011).

7. Aschoff, J. Exogenous and endogenous components in circadian rhythms. Cold Spring Harb. Symp. Quant. Biol. 25, 11-28 (1960).

8. Pittendrigh, C. \& Daan, S. A functional analysis of circadian pacemakers in nocturnal rodents: I-The stability and lability of spontaneous frequency. J. Comp. Physiol. 106, 291-331 (1976).

9. Duong, H. A., Robles, M. S., Knutti, D. \& Weitz, C. A Molecular mechanism for circadian. Science (80-). 332, 1436-1439 (2011).

10. Lande-Diner, L., Boyault, C., Kim, J. Y. \& Weitz, C. J. A positive feedback loop links circadian clock factor CLOCK-BMAL1 to the basic transcriptional machinery. Proc. Natl. Acad. Sci. 110, 16021-16026 (2013).

11. Pittendrigh, C. \& Minis, D. H. Circadian systems: longevity as a function of circadian resonance in Drosophila melanogaster. Proc. Natl. Acad. Sci. USA 69, 1537-1539 (1972).

12. von Saint Paul, U. \& Aschoff, J. Longevity among blowflies Phormia terraenovae R.D. kept in non-24-h light-dark cycles. J. Comp. Physiol. A 127, 191-195 (1978).

13. Wyse, C. A., Coogan, A. N., Selman, C., Hazlerigg, D. G. \& Speakman, J. R. Association between mammalian lifespan and circadian free-running period: the circadian resonance hypothesis revisited. Biol. Lett. 6, 696-698 (2010).

14. Libert, S., Bonkowski, M. S., Pointer, K., Pletcher, S. D. \& Guarente, L. Deviation of innate circadian period from $24 \mathrm{~h}$ reduces longevity in mice. Aging Cell 11, 794-800 (2012).

15. Bons, N., Rieger, F., Prudhomme, D., Fisher, A. \& Krause, K. H. Microcebus murinus: a useful primate model for human cerebral aging and Alzheimer's disease? Genes Brain Behav. 5, 120-130 (2006).

16. Joly, M., Ammersdörfer, S., Schmidtke, D. \& Zimmermann, E. Touchscreen-based cognitive tasks reveal age-related impairment in a primate aging model, the grey mouse lemur (Microcebus murinus). PLoS ONE 9, (2014).

17. Languille, S. et al. The grey mouse lemur: A non-human primate model for ageing studies. Ageing Res. Rev. 11, 150-162 (2012).

18. Hozer, C., Pifferi, F., Aujard, F. \& Perret, M. The biological clock in gray mouse lemur: adaptive, evolutionary and aging considerations in an emerging non-human primate model. Front. Physiol. 10, 1-23 (2019).

19. Aujard, F., Cayetanot, F., Bentivoglio, M. \& Perret, M. Age-related effects on the biological clock and its behavioral output in a primate. Chronobiol. Int. 23, 451-460 (2006).

20. Pifferi, F. et al. Effects of dietary resveratrol on the sleep-wake cycle in the non-human primate gray mouse lemur (Microcebus murinus). Chronobiol. Int. 29, 261-270 (2012).

21. Perret, M. Change in photoperiodic cycle affects life span in a prosimian primate (Microcebus murinus). J. Biol. Rhythms 12, 136-145 (1997).

22. Pifferi, F. et al. Caloric restriction increases lifespan but affects brain integrity in grey mouse lemur primates. Commun. Biol. 1, 1-8 (2018)

23. Lutermann, H., Schmelting, B., Radespiel, U., Ehresmann, P. \& Zimmermann, E. The role of survival for the evolution of female philopatry in a solitary forager, the grey mouse lemur (Microcebus murinus). Proc. R. Soc. B 273, 2527-2533 (2006).

24. Génin, F. \& Perret, M. Daily hypothermia in captive grey mouse lemurs (Microcebus murinus): effects of photoperiod and food restriction. Comp. Biochem. Physiol. B Biochem. Mol. Biol. 136, 71-81 (2003).

25. Vuarin, P. et al. Shallow hypothermia depends on the level of fatty acid unsaturation in adipose and liver tissues in a tropical heterothermic primate. J. Therm. Biol. 43, 81-88 (2014).

26. Perret, M. \& Aujard, F. Regulation by photoperiod of seasonal changes in body mass and reproductive function in gray mouse lemurs M. murinus. Int. J. Primatol. 22, 5-24 (2001).

27. Hozer, C. \& Pifferi, F. Physiological and cognitive consequences of a daily 26 h photoperiod in a primate. Proc. R. Soc. B 287, 20201079 (2020).

28. Pittendrigh, C. \& Daan, S. A functional analysis of circadian pacemakers in nocturnal rodents: IV-entrainment: pacemaker as clock. J. Comp. Physiol. 106, 223-252 (1976).

29. Nakamura, T. J. et al. Age-related decline in circadian output. J. Neurosci. 31, 10201-10205 (2011).

30. Engelberth, R. C. G. J. et al. Morphological changes in the suprachiasmatic nucleus of aging female marmosets (Callithrix jacchus). Biomed. Res. Int. 2014, 1-10 (2014).

31. Zhdanova, I. V. et al. Aging of intrinsic circadian rhythms and sleep in a diurnal nonhuman primate Macaca mulatta. J. Biol. Rhythms 26(149), 159 (2011).

32. Jazwinski, S. M., Belancio, V. P. \& Hill, S. M. Circadian Rhythms and Their Impact on Aging (Vol. 7) (2017).

33. Yu, E. A. \& Weaver, D. R. Disrupting the circadian clock: Gene-specific effects on aging, cancer, and other phenotypes. Aging (Albany. NY). 3, 479-493 (2011).

34. Yang, G. et al. Timing of expression of the core clock gene Bmall influences its effects on aging and survival. Sci. Transl. Med. 8, (2016). 
35. Banks, G., Nolan, P. M. \& Peirson, S. N. Reciprocal interactions between circadian clocks and aging. Mamm. Genome 27, 332-340 (2016).

36. Cayetanot, F., Nygård, M., Perret, M., Kristensson, K. \& Aujard, F. Plasma levels of interferon- $\gamma$ correlate with age-related disturbances of circadian rhythms and survival in a non-human primate. Chronobiol. Int. 26, 1587-1601 (2009).

37. Stanewsky, R. Genetic analysis of the circadian system in Drosophila melanogaster and mammals. J. Neurobiol. 54, 111-147 (2003).

38. Helfrich-Förster, C. The circadian clock in the brain: A structural and functional comparison between mammals and insects. J. Comp. Physiol. A. 190, 601-613 (2004).

39. Krizo, J. A. \& Mintz, E. M. Sex differences in behavioral circadian rhythms in laboratory rodents. Front. Endocrinol. 5, 3-6 (2015).

40. Wever, R. A. Sex differences in human circadian rhythms: Intrinsic periods and sleep fractions. Experientia 40, 1226-1234 (1984).

41. Duffy, J. F. et al. Sex difference in the near-24-h intrinsic period of the human circadian timing system. Proc. Natl. Acad. Sci. USA 108, 15602-15608 (2011).

42. Bailey, M. \& Silver, R. Sex differences in circadian timing systems: Implications for disease. Front. Neuroendocrinol. 35, 111-139 (2014).

43. Goel, N. \& Lee, T. M. Sex differences and effects of social cues on daily rhythms following phase advances in Octodon degus. Physiol. Behav. 58, 205-213 (1995).

44. Schmid, J. Sex-specific differences in activity patterns and fattening in the gray mouse lemur (Microcebus murinus) in Madagascar. J. Mammal. 80, 749-757 (1999).

45. Terrien, J., Perret, M. \& Aujard, F. Gender markedly modulates behavioral thermoregulation in a non-human primate species, the mouse lemur (Microcebus murinus). Physiol. Behav. 101, 469-473 (2010).

46. Noiret, A. et al. Sex-specific response to caloric restriction after reproductive investment in Microcebus murinus: an integrative approach. Front. Physiol. 11, 506 (2020).

47. Perret, M. \& Aujard, F. Aging and season affect plasma dehydroepiandrosterone sulfate (DHEA-S) levels in a primate. Exp. Gerontol. 40, 582-587 (2005).

48. Aujard, F., Perret, M. \& Vannier, G. Thermoregulatory responses to variations of photoperiod and ambient temperature in the male lesser mouse lemur: a primitive or an advanced adaptive character? J. Comp. Physiol. B Biochem. Syst. Environ. Physiol. 168, 540-548 (1998).

49. Perret, M. Energetic advantage of nest-sharing in a solitary primate, the lesser mouse lemur (Microcebus murinus). J. Mammal. 79, 1093-1102 (1998).

50. Perret, M. \& Aujard, F. Daily hypothermia and torpor in a tropical primate: synchronization by 24 -h light-dark cycle. Am. J. Physiol. Regul. Integr. Comp. Physiol. 281, R1925-R1933 (2001).

51. Le Tallec, T., Perret, M. \& Théry, M. Light pollution modifies the expression of daily rhythms and behavior patterns in a nocturnal primate. PLoS ONE 8, e79250 (2013).

52. Aujard, F., Bluet-Pajot, M. T., Zizzari, P., Perret, M. \& Epelbaum, J. IGF-1: a marker of individual life-span in a primate. Ageing Res. 1, 2 (2010).

53. Breit, A. et al. Insulin-like growth factor-1 acts as a zeitgeber on hypothalamic circadian clock gene expression via glycogen synthase kinase-3 signaling. J. Biol. Chem. 293, 17278-17290 (2018).

54. Crosby, P. et al. Insulin/IGF-1 drives PERIOD synthesis to entrain circadian rhythms with feeding time. Cell 177(896), e20-909. e20 (2019).

55. Kendall, A. R., Lewy, A. J. \& Sack, R. L. Effects of aging on the intrinsic circadian period of totally blind humans. J. Biol. Rhythms 16, 87-95 (2001).

56. Monk, T. H. \& Moline, M. L. The timing of bedtime and waketime decisions in free-running subjects. Psychophysiology 26, 304-310 (1989).

57. Possidente, B., McEldowney, S. \& Pabon, A. Aging lengthens circadian period for wheel-running activity in C57BL mice. Physiol. Behav. 57, 575-579 (1995).

58. Davis, F. C. \& Viswanathan, N. Stability of circadian timing with age in Syrian hamsters. Am. J. Physiol. Regul. Integr. Comp. Physiol. 275, 6-10 (1992).

59. Schilling, A., Richard, J. P. \& Servière, J. Effect of aging on circadian activity in gray mouse lemurs. Int. J. Primatol. 22, 25-42 (2001).

60. Spoelstra, K., Wikelski, M., Daan, S., Loudon, A. S. I. \& Hau, M. Natural selection against a circadian clock gene mutation in mice. Proc. Natl. Acad. Sci. USA 113, 686-691 (2016).

61. Emerson, K. J., Bradshaw, W. E. \& Holzapfel, C. M. Concordance of the circadian clock with the environment is necessary to maximize fitness in natural populations. Evolution (NY). 62, 979-983 (2008).

62. Dal-pan, A. et al. Caloric restriction or resveratrol supplementation and ageing in a non-human primate : first-year outcome of the RESTRIKAL study in Microcebus murinus. Age (Omaha). 33, 15-31 (2011).

63. Landes, J. et al. State transitions: a major mortality risk for seasonal species. Ecol. Lett. 20, 883-891 (2017).

64. Cox, D. R. \& Oakes, D. Analysis of Survival Data. Monographs on Statistics and Applied Probability. (Chapman\&Hall, London, 1984).

65. Kraus, C., Eberle, M. \& Kappeler, P. M. The costs of risky male behaviour: Sex differences in seasonal survival in a small sexually monomorphic primate. Proc. R. Soc. B Biol. Sci. 275, 1635-1644 (2008).

\section{Acknowledgements}

We are grateful to Aude Anzeray and Isabelle Hardy for their participation in the data collection.

\section{Author contributions}

Conceptualization, C.H., F.P. and M.P. Investigation, C.H. and M.P. Methodology and Formal Analysis, C.H., S.P. and F.P., Writing-Original Draft, C.H.; Writing-Review and Editing, C.H., M.P., S.P. and F.P. Supervision, F.P.

\section{Competing interests}

The authors declare no competing interests.

\section{Additional information}

Supplementary information is available for this paper at https://doi.org/10.1038/s41598-020-75068-8.

Correspondence and requests for materials should be addressed to F.P.

Reprints and permissions information is available at www.nature.com/reprints.

Publisher's note Springer Nature remains neutral with regard to jurisdictional claims in published maps and institutional affiliations. 
(c) (i) Open Access This article is licensed under a Creative Commons Attribution 4.0 International cc) License, which permits use, sharing, adaptation, distribution and reproduction in any medium or format, as long as you give appropriate credit to the original author(s) and the source, provide a link to the Creative Commons licence, and indicate if changes were made. The images or other third party material in this article are included in the article's Creative Commons licence, unless indicated otherwise in a credit line to the material. If material is not included in the article's Creative Commons licence and your intended use is not permitted by statutory regulation or exceeds the permitted use, you will need to obtain permission directly from the copyright holder. To view a copy of this licence, visit http://creativecommons.org/licenses/by/4.0/.

(C) The Author(s) 2020 